\section{Regulation, not private enterprise, is the key to a healthy environment}

Sir - Gretchen C. Daily and Brian H. Walker write in their Commentary "Seeking the great transition" (Nature 403, $243-245$; 2000) about the importance of involving the private sector in maintaining a stable and wholesome environment. They are, of course, correct, and industry has made a variety of efforts towards improving efficiency, recycling waste and conserving environmental quality.

However, many other examples reveal that the private sector cannot be left to regulate itself. In general, the purpose of industry is profits, not the public good or public service. Protracted fights over lead in petrol, agricultural poisons in food, and industrial waste contaminating rivers and land have burned into the public's mind the necessity for strict regulation of industrial practice. Blatant distortions of truth by the tobacco industry and the Global Climate Coalition have added to this concern. Simple exhortations are not enough.

I agree with Daily and Walker that the scientific community must participate more in defining where the public interest lies. But this definition has to do with the chemistry and physics of environment and the rules necessary for keeping the environment functioning as an appropriate place for humans and other life. Economic and political objectives are inadequate, except as they strengthen compliance with ecological and environmental needs.

The public must keep asking questions: what is clean water, clean air, an appropriate place to live, and appropriate behaviour on the part of one's close neighbours?

We look to governments to establish those rules. Where central governments fail, the rules are established locally, as for example in many communities in the Amazon Basin. The realization of the need for rules emerges from the recognition that resources are limited and are contested among diverse interests - in many cases including exogenous industry seeking an opportunity to exploit resources already being used by indigenous people.

Democratic capitalism must be developed much more intensively and deliberately. Scientists can play their part, by defining what is required for a human habitat so that the public can know what is in its interest and what is not. Relinquishing those decisions to commerce and industry has never worked in the past, it does not work now, and it will not work in the future.

Hence, although I agree with much of Daily and Walker's argument, I think they are too dismissive of governments' potential to address the challenges of protecting our environment.

George M. Woodwell

The Woods Hole Research Center, PO Box 296, Woods Hole, Massachusetts 02543, USA

\section{England and US corner the journal market}

Sir - Here I describe what I believe is the first study of the distribution of biomedical publications in Medline with respect to publishers' location. Previous studies have looked at the location of the first author, including the number of publications by country ${ }^{1}$, by US state ${ }^{2}$ or in the European Union $^{3}$, normalized to population size, number of doctors in the country concerned $^{4}$ or gross domestic product ${ }^{3}$.

I searched every year from 1966 to 1998 , using Medline Express, selecting the field "country of publication" combined with “publication year”. I carried out this search for 194 countries. The number of publications listed in Medline increased every year: from 174,584 in 1966 to 417,944 in 1998, an average annual increase of $2.76 \%$.

Just 12 countries (Fig. 1) each published more than 1\% of the total: during 1996-98, their combined share averaged $88.9 \%$. Publishers from 25 other countries contributed $0.1-1 \%$; 28 countries $0.01-0.1 \%$; and 34 countries less than $0.01 \%$ (but more than zero).

Surprisingly, 95 countries failed to contribute a single article. Most of these are smaller, underdeveloped countries with low scientific output, possibly reflecting Medline's exclusion of journals published in developing countries ${ }^{5}$.

When I analysed the 12 countries in which most journals are published, four had increased their share of publications: the United States was up from $31.64 \%$ in 1966 to $46.96 \%$ in 1998; England from 9.32 to $18.46 \%$; the Netherlands from 2.01 to

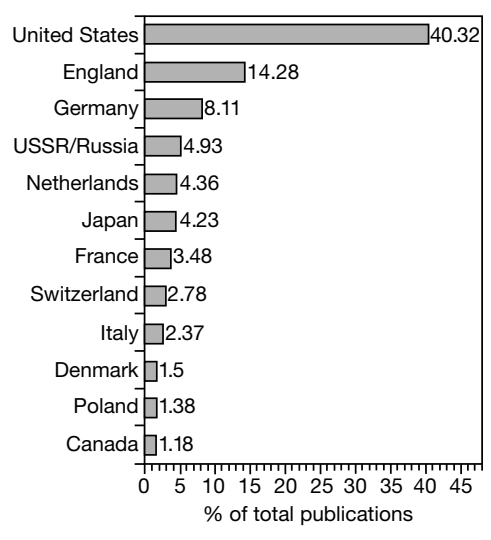

Figure 1 The percentage of biomedical publications in journals edited in the 12 most prolific countries from 1966 to 1998.
5.26\%; and Denmark from 1.15 to $1.65 \%$. Publishers from the 12 countries contributed $90.1 \%$ of the total output in 1998 , compared with $86.19 \%$ in 1966.

The proportion decreased in Germany from $9.85 \%$ to $5.79 \%$; the Soviet Union/ Russia from 8.67 to $1.52 \%$; Japan from 5.08 to $3.08 \%$; France from 5.92 to $2.14 \%$; Switzerland from 2.6 to $2.19 \%$; Italy from 5.54 to $1.33 \%$; Poland from 2.87 to $0.59 \%$; and Canada from 1.54 to $1.13 \%$.

A. A. Waheed

Department of Protein Biochemistry, Tokyo Metropolitan Institute of Gerontology, 35-2 SakaeCho, Itabashi-ku, Tokyo 173-0015, Japan

1. Benzer, A. et al. Lancet 341, 247 (1993).

2. Thompson, D. F. N. Engl. J. Med. 340, 817-818 (1999). 3. Hefler, L., Tempfer, C. \& Kainz, C. Lancet 353, 1856 (1999). 4. Eldor, J. Lancet 341, 634 (1993).

5. Rosselli, D. Lancet 354, 517 (1999).

\section{Celera's role in opening up new frontiers}

Sir - I would like to set the record straight about my closing statement at the House Science Subcommittee on Energy and Environment hearing on the Human Genome Project (Nature 404, 691; 2000).

Your reporter wrote that I said "Government's role is to initiate research on which private sector companies can capitalize, pointing to Celera Genomics as a prime example" and that I "endorsed the way that Celera is incorporating the public Human Genome Project's data into its own database, adding its own sequence information, providing annotation tools, then selling it".

This is a misleading interpretation of my views, and of comments that I made to your reporter and during the hearing (see http:// www.house.gov/science/106_hearing.htm \#energy_and_environment). What I sought to express is an optimistic view of the benefits of federal research, including technology transfer to the private sector.

In closing, I noted the role of the US federal government in settling the American West and in the development of the Internet. I said "Think what would have happened if the Defense Advanced Research Projects Agency had stepped forward and insisted that the public interest could not be served unless it controlled the content and rate of growth of the Internet. Dr Venter and others are responsible for speeding up the sequencing of the human genome by five years. For this reason at least, I would rather have the problems of private-sector involvement in the human genome field than not. Some problems are good to have, and I think this is one of them."

Ken Calvert

US House of Representatives Subcommittee on Energy and Environment, Rayburn House Office Building, Washington DC 20515-6301, USA 


\section{Don't dismiss chlorine; it could help us to avoid the fate of the Romans}

\author{
Sir - In his book Pandora's Poison: On
} Chlorine, Health and a New Environmental Strategy, recently reviewed by Terry Collins (Nature 406, 17-18; 2000), Joe Thornton advocates a broad policy that would require industry to phase out chlorinebased technologies in favour of cleaner alternatives. He says we must do away with a regulatory system that looks at one chemical at a time, and replace it with a precautionary approach that addresses major classes of chemicals and industrial processes.

Considering all organochlorines, from essential non-toxic PVC to the very toxic 2,3,7,8-TCDD (dioxin), as one class to be discarded is as non-scientific as saying that all reptiles and birds are dangerous because some snakes are venomous.

There is no scientific basis for regulating all hydrocarbons - from non-toxic polyethylene (PE) to very toxic polycyclic aromatic hydrocarbons (PAHs) such as benzo(a)pyrene - as one class. Nor is there any scientific basis for regulating nitrogencontaining organics, from nylon to nitroPAHs (the most powerful mutagens ever found, contained in diesel motor exhaust). Such a broad-based precautionary principle would mean that chlorine, nitrogen and every other organic material would be banned.

Chlorine is a very reactive element , making reactions possible that otherwise would be very difficult to perform without much more energy or more pollution. Chlorine is used in chains of processes: it is first used to make the building blocks for polyurethane and the remaining $\mathrm{HCl}$ is used to make PVC. That halves the energy needed to make chlorine for both. Without chlorine, the amount of (toxic) waste from polyurethane manufacturing would be much higher.

Thornton has been quoted in the online Environment News Service (http://ens. lycos.com/ens/jun2000/2000L-06-08-06. $\mathrm{html}$ ) as warning that levels of dioxin in the environment can only increase, as long as organochlorines are produced. He claims that there is no safe way to dispose of them: "once they're in you, there's no way to get them out".

This is a clear untruth. In every Western country the levels of DDT/DDE, PCBs and dioxins in the environment and in animals and humans have fallen or are falling rapidly since these industrial products and byproducts have been banned or restricted. PCB levels in North Sea fish are now half what they were ten years ago. The dioxin content of Belgian mothers' milk has gone down by $30 \%$ in five years - mainly because of the stringent measures that were imposed on incinerators - during a period when chlorine and PVC production, use and incineration were higher than ever before.

"Like the Romans, who sipped from lead cups, ran drinking water through lead pipes, and bathed in lead basins, we have built our house of poison unaware of the consequences," Thornton says.

But unlike the Romans, who were likely to die by the age of 40 either from lead poisoning or as a result of infections, today's Westerners reach 80 years and older. In my view, this is not least thanks to drinking chlorinated water run through PVC pipes, swimming in chlorinated pools, eating food sealed in PVC-wrap foil, sleeping on mattresses made using chlorine and taking medicines of which $80 \%$ are made with the help of chlorine.

Ferdinand Engelbeen

Chlorophiles (an independent organization of workers in the chlorine/PVC industry), Oude Ertbrandstraat 12, B-2940 Stabroek, Belgium

\section{Bright future in the stars for big telescopes?}

Sir — We would like to correct a misleading impression left by your News article on the new Green Bank Telescope (GBT) (Nature 406, 816: 2000), which achieved first light on 22 August 2000. Funding for the GBT was appropriated by Senator Robert Byrd (Democrat, West Virginia) not with an earmark, but with a $\$ 75$ million addition to the already established 1989 NSF budget.

While it is true, as your reporter wrote, that the project has taken considerably longer than initially planned, the telescope is not "tens of millions of dollars over budget", as it was built under a fixed-price contract. It is correct that claims by the contractor seeking additional payment are in arbitration, but your story appears to anticipate the arbitrator's decision while the hearing is still in progress.

More important, though, your article leaves the impression that the GBT stands alone as the "last of the giants", and that use of large single dishes is being superseded by other approaches.

On the contrary, there has been a resurgence in the use of single-dish telescopes, stimulated in part by astronomical discoveries, but also by the development of active reflecting surface technology and focalplane array detectors. As well as the GBT, large single-dish telescopes are under construction in Sardinia and Mexico and one is planned in China. Major upgrades have been undertaken to instruments in
Puerto Rico, France, Germany and the United Kingdom. Single-dish telescopes are a critical component of world astronomical capability.

P. R. Jewell ${ }^{\star}$, F. J. Lockman ${ }^{\star}$, T. M. Bania $\dagger$

${ }^{*}$ National Radio Astronomy Observatory, PO Box 2, Green Bank, West Virginia 24944, USA

†Astronomy Department, Boston University, 725 Commonwealth Avenue, Boston,

Massachusetts 02215, USA

\section{Non-scientists thanked for vital help in Kansas}

Sir - We appreciated your News story (Nature 406, 552-553; 2000) about the role of scientists in restoring modern science standards to elementary and high-school classes in Kansas. We would like to point out, however, that our efforts, and the similar efforts of scientists in New Mexico, would have come to nought without the many non-scientists who were willing to devote hundreds of hours to this issue, and who were willing to drag us out of the laboratory.

The success of groups like Kansas Citizens for Science depends on the combined efforts of people with backgrounds in many fields, not just science, as well as support from national organizations such as the National Center for Science Education. When many are involved, the effort required from each scientist does not detract from research.

Despite the temporary debacle over science standards, Kansas is one of the highest-ranked US states in educational achievement. High expectations in science for high-school graduates can only make our job as educators and researchers easier. We urge readers to examine science standards in their area, then look for supportive non-scientists to help ward off attempts by creationists or other groups to bring religion into the science classroom.

\section{Matthew Buechner}

Department of Molecular Biosciences, 8035

Haworth Hall, University of Kansas, Lawrence, Kansas 66045-2106, USA

Other signatories to this letter:

Adrian Melott Department of Physics and Astronomy, University of Kansas

Robert Hagen Departments of Ecology and Evolutionary Biology, University of Kansas

Philip Baringer Department of Physics and Astronomy, University of Kansas

Patrick Ross Department of Biology, Southwestern College, Kansas Keith M. Ashman Physics Department, Baker University, Kansas

\section{Erratum}

In a letter about journals (A. A. Waheed Nature 405, 613; 2000), the third paragraph should start: "Just 12 countries each published more than $1 \%$ of the total: from 1966 [not 1996] -1998 their combined share averaged 88.9\%." 